\title{
STRATEGI PENGEMBANGAN KEMAMPUAN MEMBACA ANAK USIA 4-5 TAHUN MELALUI PERMAINAN ULAR TANGGA
}

\author{
Ana Nur Hidayah ${ }^{\mathbf{1}}$, Veny Iswantiningtyas ${ }^{2}$, Ridwan ${ }^{3}$ \\ Prodi. PG-PAUD, FKIP, Universitas Nusantara PGRI Kediri ${ }^{123}$ \\ ananurhidayah17@gmail.com
}

\begin{abstract}
The problem faced in this study is the reading ability of children aged 4-5 years old is still low, it is caused by teachers who tend to use classical learning strategies when introducing letters or words. To develop the reading ability of children aged 4-5 years old must be adjusted to the characteristics of early childhood, namely learning through play. One form of game stimulation that is able to develop children's reading skills is the snake and ladder game, by using the snake and ladder game in learning, it is expected that children's reading ability of 4-5 years old will develop optimally. This research uses the action research method, while the research design used is in the form of a cycle that refers to the Kemmis and Mc Taggrat models with the following steps: 1) planning, 2) action, 3) observation, 4) reflection. In this study only reached the planner stage, namely making RRPM, RPPH and snake ladder games that have been modified by researchers to develop reading skills in children aged 4-5 years old, then the learning device is validated by experts and declared to meet practical aspects so that it is feasible to use to develop language skills of children aged 4-5 years old. The population in this study were children aged 4-5 years old at Dharma Wanita I Rowoharjo Nganjuk Kindergarten in 2019/2020, taking a sample of 18 children consisting of 11 boys and 7 girls.
\end{abstract}

Keywords: Reading ability, Children aged 4-5 years, Snakes and Ladders game.

\section{PENDAHULUAN}

Membaca merupakan suatu kegiatan untuk memperoleh suatu pengetahun serta informasi. Kepandaian membaca pada umumnya diperoleh dari sekolah. Kepintaran dalam membaca merupakan suatu keterampilan yang sangat unik dan berperan penting bagi perkembangan ilmu pengetahuan serta sebagai alat komunikasi bagi kehidupan setiap manusia. Oleh sebab itu seseorang akan memperoleh informasi dan ilmu pengetahuan yang baru dengan membaca. Aktifitas membaca sangat diperlukan oleh siapapun yang menginginkan kemajuan dan peningkatan diri, karena membaca dapat meningkatkan daya pikiran dan mempertajam pandangan, serta menambah wawasan, Hadini (2017).

Mengajarkan membaca sejak dini kepada anak perlu dilakukan, sebab anak mempunyai rasa ingin tahu yang banyak serta mudah sekali menyerap segala sesuatu yang diajarkan dengan baik selama dalam batas-batas aturan perkembangan pra sekolah. Menurut Steinberg (dalam Susanto, 2011) membaca dini adalah membaca yang diajarkan secara terprogram pada anak prasekolah. Program ini menumpukkan perhatian pada perkataanperkataan utuh, bermakna dalam konteks pribadi anak-anak dan bahan yang diberikan melalui permainan dan kegiatan yang menarik sebagai perantara pembelajaran.

Rencana pengembangan kemampuan membaca di Taman Kanak-kanak yaitu dengan menggunakan media pembelajaran berupa alat peraga atau alat permainan yang dapat digunakan oleh guru dan anak saat kegiatan pembelajaran. Salah satu permainan yang bisa digunakan oleh guru taman kanak-kanak untuk mengembangkan kemampuan membaca adalah permainan ular tangga. permainan ular tangga adalah permainan yang menggunakan papan bergambar motif kotakkotak bertuliskan angka 1-100, akan tetapi pembuatan tidak bisa disesuaikan sesuai dengan fungsi dan tujuan permainan dan tidak ada aturan 
pasti. Permainan ular tangga ini menggunakan dadu yang mempunyai enam sisi dan juga bidk untuk dijalankan. Apabila bidak berada dibawah tangga maka bidak bisa naik ke ujung tangga, sedangkan apabila bidak berada dibawah kepala ular maka bidak harus turun menuju ke ekor ular. Apabila dadu menunjukkan angka enam pemain bisa melempar dadu sebanyak dua kali, Ningtyas (2014). Lebih lanjut Suyanto (dalam Yuvitasari, 2015) menjelaskan bahwa permainan ular tangga kata cukup efektif untuk mengembangkan kemampuan mengenal kata pada anak usia 5 sampai 6 tahun, karena pada usia tersebut anak berada pada tahap pra operasional.

Bersumber pada hasil observasi yang peneliti lakukan pada anak kelompok A Taman Kanakkanak Dharma Wanita 1 Rowoharjo Kecamatan Prambon Kabupaten Nganjuk tentang kemampuan membaca masih sangat kurang bahkan jauh dari indikator yang hendak di capai. Hal ini tampak ketika kegiatan membedakan kata-kata yang memiliki huruf awal yang sama, masih banyak anak yang kesulitan bahkan ada yang belum mengenal huruf. Selain itu masih banyak anak yang diam saja ketika guru menunjukkan kata dan meminta anak untuk membaca, bahkan yang mampu membedakan huruf hanya 6 anak sedangkan jumlah anak seluruhnya adalah 18 anak. Dari hasil wawancara yang dilakukan kepada guru diketahui bahwa kemampuan membaca anak yang belum berkembang sebanyak 6 anak, mulai berkembang sebanyak 8 anak, berkembang sesuai harapan sebanyak 3 anak dan yang berkembang sangat baik sebanyak 1 anak. Sebelum menggunakan permainan ular tangga, yang sudah dilakukan di TK Dharma Wanita 1 Rowoharjo adalah dengan menerapkan model pembelajaran klasik, menggunakan kartu huruf, akan tetapi tidak efektif dan tidak semua anak tertarik untuk memperhatikan guru, oleh sebab itu guru dan peneliti mengganti media pembelajaran agar semua anak tertarik untuk mengikuti pelajaran yaitu dengan permainan ular tangga.

Sesuai hasil observasi tersebut, maka peneliti berkolaborasi dengan guru membuat penelitian tindakan untuk mengembangkan kemampuan membaca anak usia 4-5 tahun di Taman Kanakkanak Dharma Wanita 1 Rowoharjo Kecamatan Prambon Kabupaten Nganjuk, dengan menggunakan permianan ular tangga yang berbeda dengan permainan ular tangga biasa, mulai dari media dan cara bermainnya dimodifikasi untuk memaksimalkan kemampuan membaca anak 4-5 tahun kelompok A Taman Kanak-kanak Dharma Wanita 1 Rowoharjo Nganjuk.

Penelitian yang relevan yang sesuai dengan topik penelitian ini antara lain : 1) guided reading: a research-based response to the challenges of early reading instructtion, (Iaquinta dalam ningtyas, 2014) penelitian ini berfokus pada bagaimana guru mengajarkan membaca kepada anak, peneliti menghasilkan suatu cara panduan membaca yang dapat dilakukan oleh guru kepada anak yaitu dengan cara mengajarkan membaca dengan mudah pada saat anak sedang mulai belajar membaca awal. 2) peningkatan kemampuan membaca permulaan melalui permainan ular tangga, Ningtyas (2014) penelitian ini juga memfokuskan bagaimana guru menyediakan permainan ular tangga untuk meningkatkan kemampuan membaca, penelitian ini menghasilkan suatu permainan ular tangga yang mengajarkan anak menggenal huruf, mengenal suku kata dan kata, membaca kalimat sederhana dan memaknai kata. 3) peningkatan kemampuan membaca anak melaui permainan dadu suku kata di Taman Kanak-kanak Aisiyah Agam, (Zuarny, 2012) yang menjadi inti dari penelitian ini adalah agar target kemampuan membaca bisa dicapai maka dibutuhkan suatu media pembelajaran yang menarik dan metode yang beraneka ragam.

Adapun yang menjadi tujuan pada penelitian ini adalah membuat suatu strategi pembelajaran untuk mengembangkan kemampuan membaca anak melalui permian ular tangga di Taman Kanak-kanak Dharma Wanita 1 Rowoharjo Kecamatan Prambon Kabupaten Nganjuk .

\section{METODE PENELITIAN}

Penelitian ini menggunakan pendekatan kualitatif dengan menggunakan rancangan penelitian tindakan kelas / PTK. Menurut Kemmis dan Taggart (dalam Yuliawati, dkk 2012) penelitian tindakan kelas adalah suatu penelitian refleksif diri kolektif yang dilakukan oleh pesertapesertanya dalam situasi sosial untuk meningkatkan penalaran dan keadilan praktik pendidikan dan praktik sosial mereka, serta pemahaman mereka terhadap praktik-praktek itu dan terhadap situasi tempat dilakukan praktikpraktek tersebut.

Subyek dalam penelitian adalah anak kelompok A Taman Kanak-kanak 1 Rowoharjo Kecamatan Prambon Kabupaten Nganjuk tahun ajaran 2019/2020 dengan jumlah murid sebanyak 18 anak, terdiri dari 11 anak laki-laki dan 2 anak perempuan. Penelitian ini dilakukan oleh peneliti 
sebagai guru kelas kelompok A dan dibantu oleh guru Taman Kanak-kanak.

Rencana penelitian tindakan kelas yang digunakan terdiri 2 siklus dengan 4 tahapan, dimana pada setiap siklus terdiri dari beberapa pertemuan. Adapun rancangan siklus 1 sebagai berikut : 1) perencanaan, pada perencanan ini peneliti menentukan indikator kemampuan membaca yang hendak dicapai, menyiapkan RPPM, RPPH, skenario pembelajaran, menyiapkan lembar penilaian dan menyiapkan permainan ular tangga telah dimodifikasi serta melakukan validasi ahli. Produk dari analisis uji ahli dipergunakan oleh peneliti sebagai dasar untuk memperbaiki permainan ular tangga sebagai salah satu strategi mengembangkan kemampuan membaca anak usia dini. 2) pelaksanaan tindakan, pada tahap ini peneliti melaksanaan kegiatan pembelajaran disesuaikan dengan perencaaan yang telah disusun dengan tujuan untuk meningkatkan hasil belajar, 3) pengamatan, saat ini peneliti melakukan pengamatan untuk mengetahui kesesuaian perencanaan dengan pelaksanaan tindakan yang telah dilakukan dari awal sampai akhir, dimana kegiatan ini dilakukan untuk mengetahui pencapaian tujuan yang telah diharapkan, 4) refleksi, kegiatan ini dilakukan pada saat akhir siklus. Refleksi dilakukan oleh peneliti dan guru kelas untuk mendiskusikan berbagai hal yang terjadi selama proses pembelajaran, hasil dari refleksi ini akan dipergunakan oleh peneliti untuk melakukan perbaikan perencanaan dan tindakan pada siklus 2 .

\section{PEMBAHASAN}

Sesuai kondisi awal ditemukan bahwa kemampuan membaca anak masih rendah, hal tersebut terlihat ketika anak diminta oleh guru untuk membedakan berbagai kata yang memiliki huruf awal yang sama, anak masih banyak yang kesulitan dan ada juga anak masih belum mengenal huruf. Selain itu masih ada anak yang diam saja pada saat guru menunjukkan kata kemudian anak diminta untuk membacanya

Situasi tersebut membuat peneliti perlu melakukan suatu upaya perbaikan dalam kegiatan pembelajaran untuk mengembangkan kemampuan membaca anak ketika membedakan berbagai kata yang memiliki suku kata awal yang kembar. Peneliti bersama guru kelas berkolaborasi untuk melakukan suatu kegiatan perbaikan yaitu dengan mengganti media pembelajaran berupa permianan ular tangga yang telah dimodifikasi oleh peneliti supaya semua anak tertarik untuk mengikuti pelajaran. Kegiatan pembelajaran ini dikemas dalam bentuk permainan, sesuai pendapat yang dikemukanakan oleh Mayke (dalam Sudono dalam Wulandari, 2017) bahwa melalui bermain dapat memberikan kesempatan kepada anak untuk menemukan sendiri, memanipulasi, berekplorasi serta mendapatkan berbagai macam ide baru yang tak terkirai. Selain itu Sonowat dan Francis (dalam Ningtyas, 2014) menjelaskan bahwa kemampuan membaca anak akan diperoleh melewati proses alami yaitu anak akan belajar melihat huruf, gambar, kata serta membaca buku cerita andaikan anak mengikuti berbagai tahapan dengan baik, maka anak akan berhasil didalam berlatih atau belajar membaca.

Sesuai uraian diatas bisa dibuat suatu media pembelajaran berupa permianan ular tangga yang dimodifikasi untuk mengembangkan kemampuan membaca. Permainan ular tangga ini mengajarkan anak mengetahui huruf setelah itu diajarkan untuk membaca suku kata, apabila anak sudah bisa membaca suku kata kemudian anak diajarkan untuk membaca kata dan dilanjutkan untuk diajari membaca kalimat serta memaknainya. Pada permainan ini lebih mengutamakan proses ketika pengajaran membaca tanpa memaksa sebab anak melakukannya dengan gembira dan anak mau melakukan lagi ketika guru mengajaknya bermain.

Peneliti mencoba merancang media permianan ular tangga untuk mengembangkan kemampuan membaca anak. Ular tangga ini berukuran $50 \mathrm{~cm} \mathrm{x}$ $50 \mathrm{~cm}$ setiap kotaknya, jumlah kota terdiri dari 36 kotak terdiri dari 1 kotak bertuliskan "mulai dan 1 kotak bertulisakan "hebat" sisanya 26 kotak akan berisi tulisan huruf a sampai $\mathrm{z}$ dan angka. Selain itu terdapat gambar buah-buahan dalam setiap kotak untuk menarik minat anak. Kotak atau papan pada ular tangga ini terbuat dari banner yang telah di desain semenarik mungkin untuk membangkitkan minat anak dalam memainkannya dan disesuaikan dengan keadaan di lembaga, pada permainan ular tangga ini yang dijadikan bidak adalah anak sendiri sehingga anak lebih senang karena bisa berekplorasi secara langsung.

Permainan ular tangga ini telah melalui uji dua orang validator yakni ahli materi dan media pembelajaran pembelajaran pendidikan anak usia dini. Hasil dari penilaian oleh dua orang validator tersebut menyatakan, bahwa permainan ular tangga yang telah peneliti modifikasi memenuhi aspek praktis sehingga layak digunakan untuk mengembangkan kemampuan membaca anak usia 4-5 tahun. Berikut ini bentuk desain permainan 
ular tangga yang telah peneliti modifikasi. Seperti pada gambar di bawah ini :

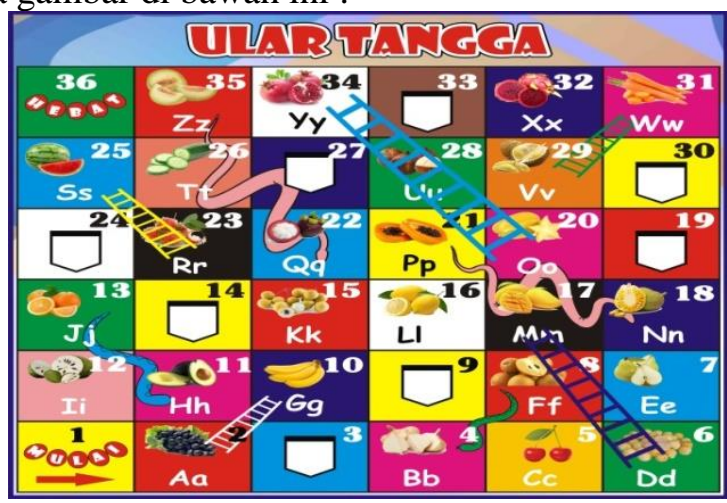

Gambar 1. Permainan Ular Tangga untuk mengembangkan kemampuan membaca anak.

Adapun langkah Langkah-langkah dalam permainan ular tangga dalam penelitian ini yaitu:

1. Menggunakan sebuah dadu untuk menjalankan bidak

2. Seluruh pemain memulai permainan dari kotak "mulai" dan berakhir di kotak "hebat".

3. Terdapat 5 tangga dan 4 ular pada kotak tertentu serta 8 kotak yang berisi kartu kata.

4. Ekor ular mengarahkan pemain untuk mundur sesuai dengan gambar ular, sedangkan gambar tangga mengarahkan pemain maju sesuai dengan gambar tangga.

5. Setiap pemain yang berhenti pada kotak yang terdapat kantong maka pemain harus mengambil kartu dan membacanya. Apabila pemain bisa membacanya dengan benar maka pemain boleh melanjutkan perjalanan menuju kotak selanjutnya sesuai dengan hasil putaran angka dadu, namun jika pemain salah dalam membaca kartu kata maka pemain harus tetap berada pada kotak kantong tersebut

6. Menentukan giliran bermain dengan cara hompipah dan suit untuk yang terakhir

7. Jika telah mengetahui urutan bermain, pemain pertama hingga pemain terakhir berdiri pada posisi mulai sesuai urutan masing-masing.

8. Pemain pertama melempar dadu dan berjalan sesuai mata dadu yang muncul, di lanjutkan dengan pemain berikutnya hingga pemain terakhir.

9. Pemain yang mencapai kotak "hebat " pertama kali dinyatakan sebagai pemenang.

\section{SIMPULAN DAN SARAN 4.1. Simpulan}

Berdasarkan hasil prapenelitian diperoleh data bahwa kemampuan membaca anak masih rendah, oleh karena itu guru dan peneliti berkolaborasi untuk mengganti media pembelajaran agar semua anak tertarik untuk mengikuti pelajaran yaitu dengan permainan ular tangga. Lebih lanjut permainan ular tangga ini telah divalidasi oleh ahli dan dinyatakan memenuhi aspek praktis, sehingga layak digunakan untuk mengembangkan kemampuan membaca anak usia 4-5 tahun. Melalui permainan ular tangga yang diterapkan dalam proses pembelajaran pada anak kelompok A Taman Kanak-kanak 1 Rowoharjo Kecamatan Prambon Kabupaten Nganjuk tahun ajaran 2019/2020 diharapkan dapat menciptakan suasana belajar yang kreatif, aktif dan menyenangkan sehinga kemampuan membaca anak dapat berkembang optimal.

\subsection{Saran}

Berdasarkan kesimpulan di atas, peneliti memberikan saran sebagai berikut :

1. Sebaiknya dalam penggunaan ular tangga ini guru membagi anak ke dalam beberapa kelompok.

2. Pembagian kelompok harus dilakukan secara merata yaitu anak- anak yang aktif di buat satu kelompok dengan anak- anak yang pendiam, sehingga permainan akan berjalan secara seimbang.

\section{REFERENSI}

Hadini, Nining. (2017). Meningkatkan Kemampuan Membaca Anak Usia Dini melalui Kegiatan Permainan Kartu Kata di TK Al-Fauzan Desa Ciharashas Kecamatan Cilaku Kabupaten Cinajur. Jurnal Empowerment. 6 (1), 19-25. Bandung: STKIP Siliwangi

Susanto, Ahmad. (2011). Perkembangan Anak Usia Dini Pengantar dalam Berbagai Aspeknya. Jakarta : Kencana Pranada Media Group.

Ningtyas, Dhita P. (2014). Peningkatan Kemampuan Membaca Permulaan melalui Permainan Ular Tangga. Jurnal Pendidikan Anak Usia Dini. 8 (2), 241-250. Jakarta: Universitas Negeri Jakarta.

Wulandari, (2017). Pengaruh Media Permainan Ular Tangga Terhadap Kemampuan Mengenal Lambang Bilangan 1-10 pada 
Kelompok A di RA As-Syuhada Pedurungan Semarang tahun ajaran 2016/2017. PAUDIA: Jurnal Penelitian dalam Bidang Pendidikan Anak Usia Dini. 6 (1), 25-34. Semarang : Universitas PGRI Semarang.

Yuliawati, Fitri, dkk. (2012). Penelitian Tindakan Kelas Untuk Tenaga Pendidik Profesional. Sleman: Pedagogia

Yuvitasari, Intan. (2015). Peningkatan Kemampuan Mengenal Kata Melalui Metode Permainan Ular Tangga Kata pada anak Kelompok A TK Sinar Melati Sariharjo Ngaglik Sleman Yogyakarta. Skripsi. Universitas Negeri Yogyakarta http://journal.student.uny.ac.id/ojs/index.php/ pgpaud/article/viewFile/121/115. Diakses 18 mei 2020

Zuarny, Wani. (2012). Peningkatan Kemampuan Membaca Anak Melalui Permianan Dadu Suku Kata di Taman Kanak-Kanak Aisiyah Agam. Jurnal Persona PAUD. 1(1), 3-14 . Padang : Universitas Negeri Padang. 